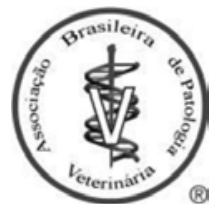

Diagnostic exercise From The Latin Comparative Pathology Group and

Diagnostic Exercise

From The Latin Comparative Pathology Group*

\title{
Bovine congenital babesiosis
}

Contributors:

Luan Cleber Henker**, Marina Paula Lorenzett, Saulo Petinatti Pavarini ${ }^{1}$.

${ }^{1}$ Veterinary Pathology Laboratory, Universidade Federal do Rio Grande do Sul (UFRGS), Porto Alegre, Rio Grande do Sul, 91540-000, Brazil

**Corresponding author: E-mail: luanchenker@gmail.com.

\section{Clinical History:}

A crossbred, stillborn bovine fetus, with nine months of gestation, was submitted for postmortem examination. The dam that aborted was a 2-year-old heifer that did not have any additional clinical signs. The owner observed several late-term abortions and stillbirths in this farm during the referred calving season.

\section{Necropsy and Microscopic Findings:}

Necropsy findings included moderate accumulation of light red fluid in the abdominal and thoracic cavities, mild hemoglobin imbibition, as well as collapsed lungs (Fig. 1). The liver was markedly enlarged, had rounded edges, and moderate, diffuse yellow discoloration. The gallbladder was filled with thick, grumous bile, and the spleen was moderately enlarged. The kidneys had moderate diffuse dark red discoloration, and the urinary bladder was distended with dark-red urine (Fig. 2). The grey matter of the brain and the spinal cord was markedly pink-red discolored (Fig. 3). Squashes of the spleen and brain were prepared and routinely stained with PanóticoRápido ${ }^{\circledR}$ (Laborclin, Brazil) (Fig. 4).

\section{Follow-up questions:}

- Name of the condition;

- Etiological agent;

- Mechanism of pathogen transmission in this case;

- Typical gross findings;

- Typical microscopic findings.

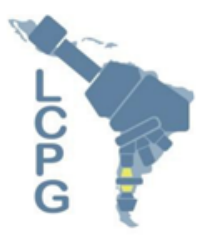

*The Diagnostic Exercises are an initiative of the Latin Comparative Pathology Group (LCPG), the Latin American subdivision of The Davis-Thompson Foundation and published in cooperation with the Brazilian Journal of Veterinary Pathology.

Editor-in-chief for this Diagnostic Exercise: Claudio Barros Associate Editor for this Diagnostic Exercise: Ingeborg Langohr.

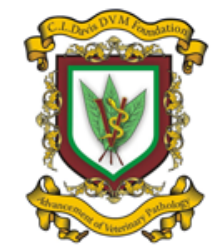


Diagnostic exercise From The Latin Comparative Pathology Group and the Davis-Thompson Foundation: Bovine Congenital babesiosis

Braz J Vet Pathol, 2021, 14(1), 70 - 74

DOI: 10.24070/bjvp.1983-0246.v14ilp70-74

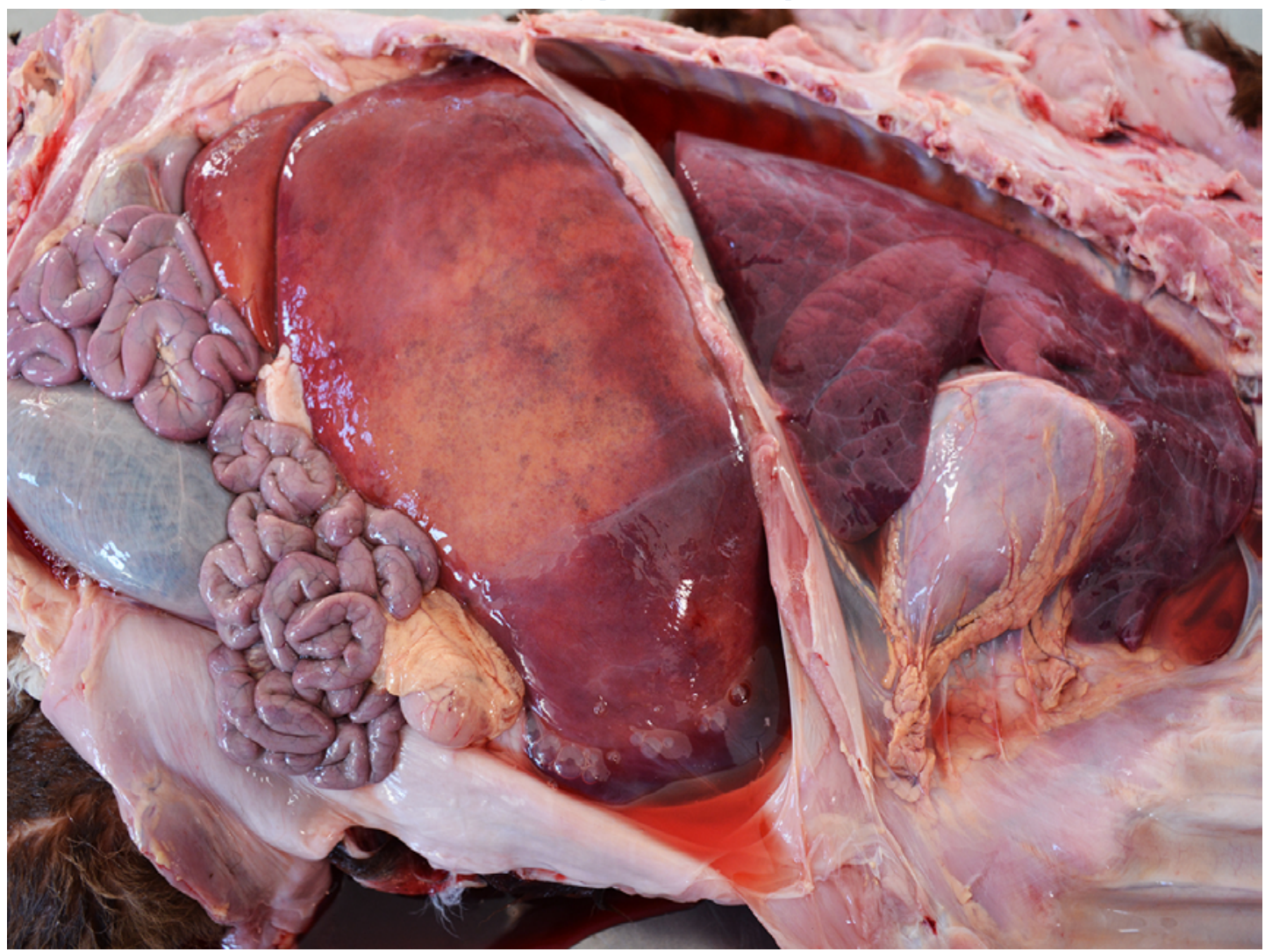

Figure 1

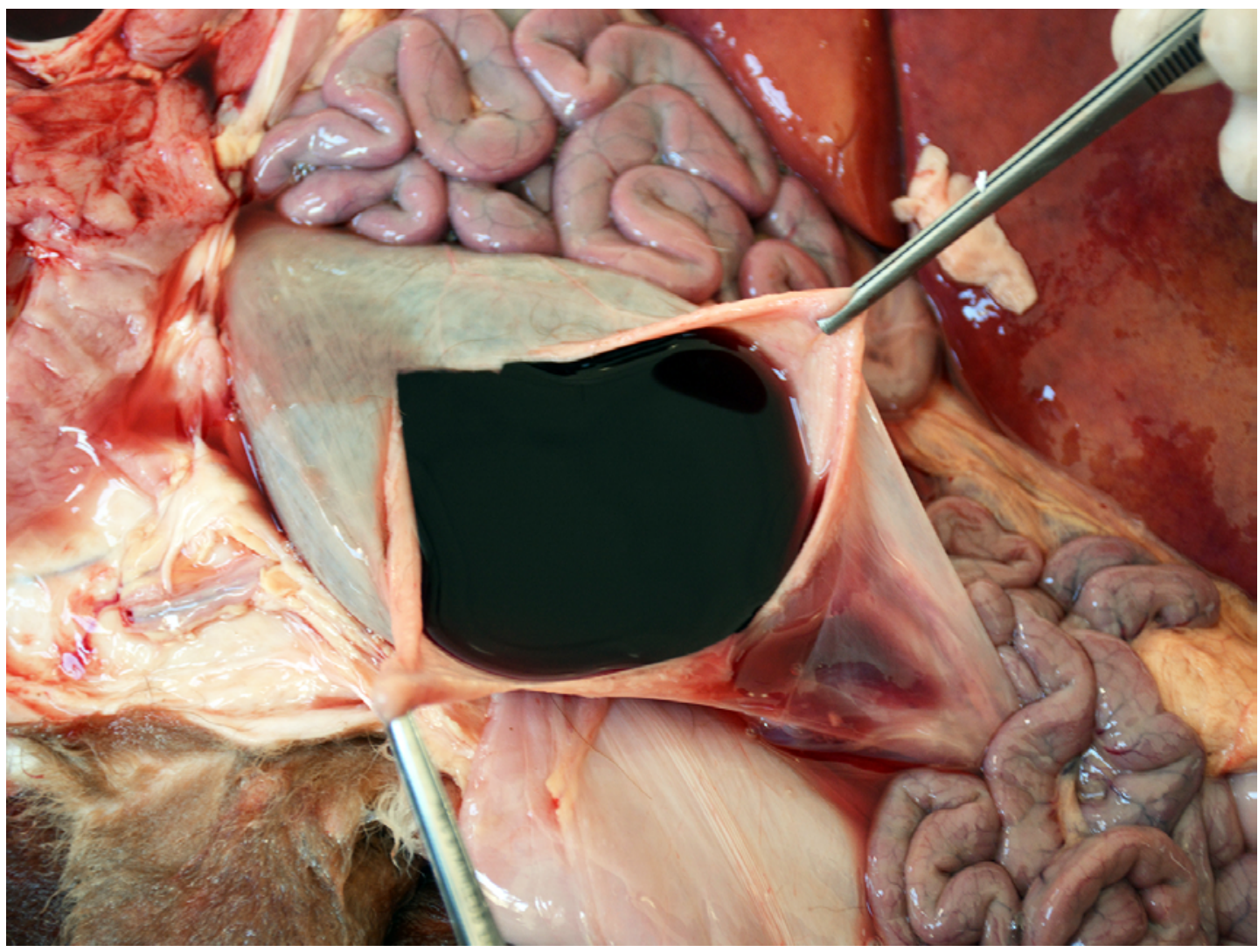

Figure 2

Brazilian Journal of Veterinary Pathology. www.bjvp.org.br . All rights reserved 2007-2021. 
Braz J Vet Pathol, 2021, 14(1), 70 - 74

DOI: 10.24070/bjvp.1983-0246.v14i1p70-74

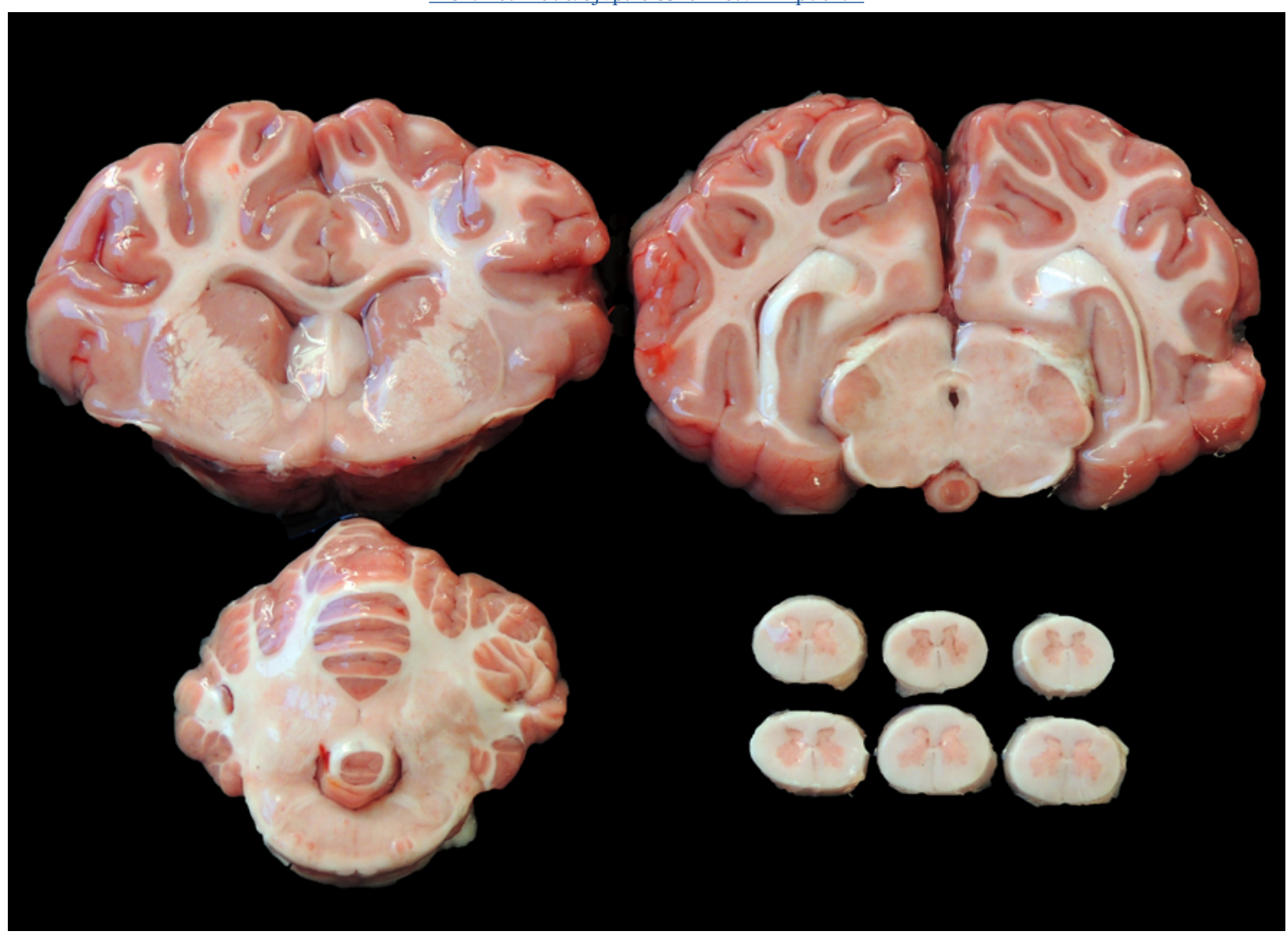

Figure 3

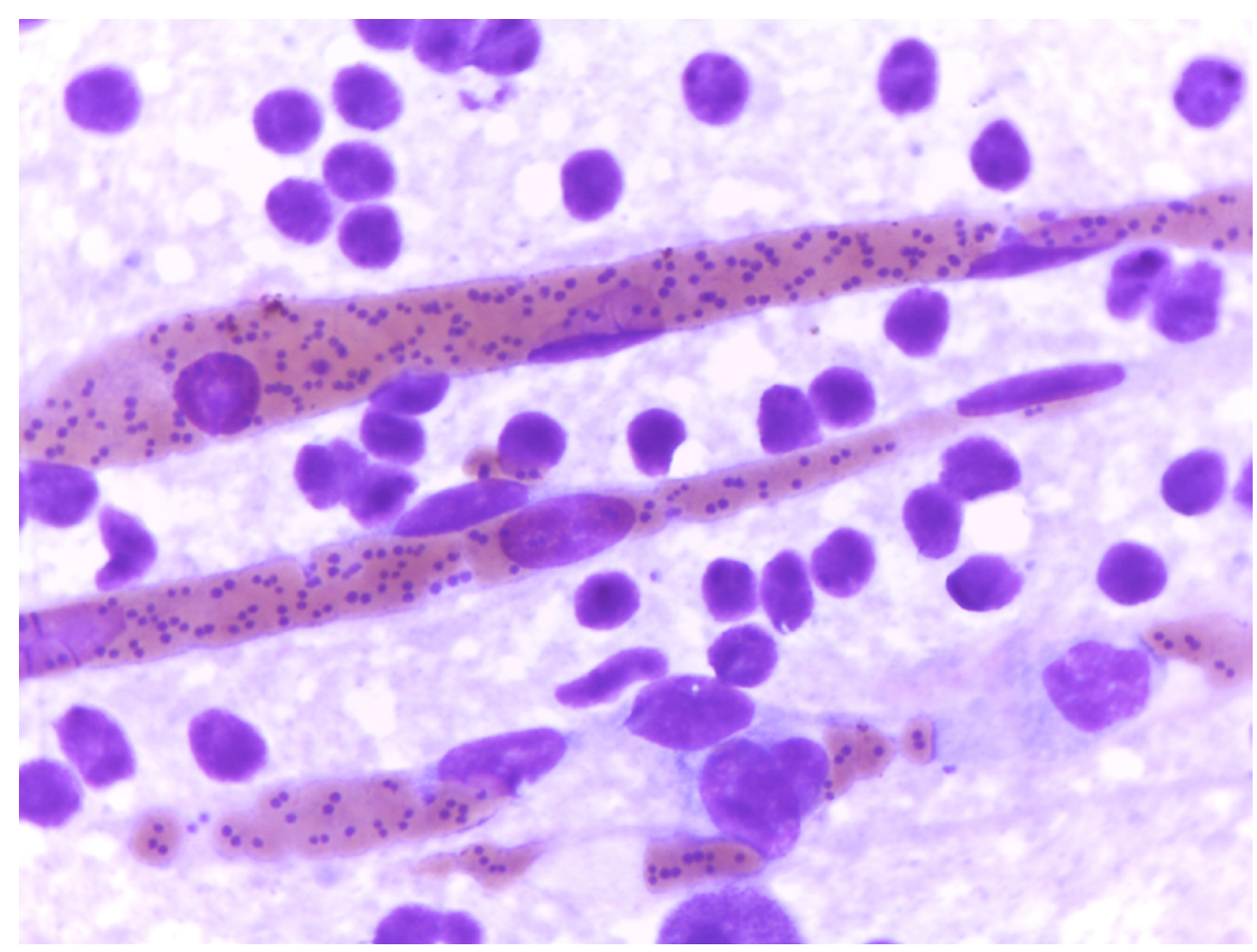

Figure 4

Brazilian Journal of Veterinary Pathology. www.bjvp.org.br . All rights reserved 2007-2021. 
- Name of the condition: Bovine babesiosis.

Braz J Vet Pathol, 2021, 14(1), 70 - 74

DOI: 10.24070/bjvp.1983-0246.v14ilp70-74
- $\quad$ Etiological agent: Babesia bovis.

- Mechanism of pathogen transmission in this case: transplacental/ vertical/ intrauterine transmission.

- Typical gross findings: Most of the findings in the present case are typical of bovine babesiosis and are identical to lesions observed in cattle of all age groups. The moderate amount of light red fluid observed in the thoracic and abdominal cavities is a common finding in aborted and stillborn fetuses, usually associated with intrauterine death and autolysis. The lungs were bright red and collapsed, indicating that the calf did not breathe. Several findings associated with bovine babesiosis, herein observed are the result of hemolysis, mainly intravascular, as well as red blood cell recycling, including splenomegaly, hepatomegaly, grumous bile, dark kidney discoloration, antemortem hemoglobin imbibition, and dark red urine (hemoglobinuria). Furthermore, in cases of Babesia bovis infection in cattle, a typical gross finding is marked diffuse congestion of the central nervous system (CNS), predominantly affecting the grey matter. The change is colloquially referred to as "cherry-pink" discoloration and the condition as "cerebral babesiosis".

- Typical microscopic findings: Cytological preparations represent a useful diagnostic tool to search for hemoparasites, e.g., Babesia bovis and Anaplasma marginale. In cases of bovine babesiosis, cytological preparations of the brain and spleen are commonly performed during the necropsy. In the former, it is possible to find capillaries packed with erythrocytes with merozoites consistent with B. bovis (Figure 4). These parasites are basophilic, commonly observed in pairs, and measure approximately $2 \mu \mathrm{m}$. Histological findings may include spleen congestion, hemosiderosis and erythrophagocytosis. The liver may have varying degrees of cholestasis and hemosiderosis, hemoglobin casts may be observed in the kidneys, and the CNS may be markedly congested. Parasites may be found in the CNS and several other organs in H\&E sections; however, the observation of parasites in histological sections is generally a difficult task.

\section{Discussion:}

Bovine babesiosis is a major cause of disease and death in cattle in several regions of Brazil (Pupin et al. 2019), especially in areas of enzootic instability, such as great part of southern Brazil (Almeida et al. 2006, Mello et al. 2017). Babesia bovis is a tick-borne disease, transmitted mainly by Rhipicephalus (boophilus) microplus (Bock et al. 2014). In addition to tick-borne transmission, transplacental transmission of this hemoparasite, as well as of $B$. bigemina and $A$. marginale, is known to occur at low levels in endemic areas (Costa et al. 2016). Rarely, these intrauterine infections have been reported to cause fetal death, leading to abortion, stillbirth or the birth of weak calves that die in the neonatal period (Trueman \& Mclennan 1987). Even though such events are considered sporadic, we have diagnosed several similar cases of babesiosis and anaplasmosis affecting fetuses and deceased newborn calves in the last few years in our laboratory (Henker et al. 2020). The exact mechanisms of fetal infection is not completely understood (Costa et al. 2016); however, it is clear that $B$. bovis as well as A. marginale infections should be considered as differential diagnoses in cases of late term abortions, stillbirths and neonatal deaths in cattle where these diseases occur (Henker et al. 2020). In cases of fetal or neonatal bovine babesiosis, gross and microscopic findings seem to be identical to those observed in cattle of all ages, and are partly the result of intravascular and extravascular hemolysis, which lead to hypoxia (Bock et al. 2014, Valli et al. 2016). Furthermore, typical gross findings include cherry-pink discoloration of the CNS grey matter, which is better evident in this anatomic region comparatively to the white matter due to its more abundant vascularization (Valli et al. 2016). In addition to direct erythrocyte damage, $B$. bovis seems to be involved in the production and release of cytokines, leading to vasodilation, hypotension, and circulatory shock (Wright et al. 1989), which could be partly responsible for the fetal death in cases of transplacental infection.

\section{References}

1. Almeida M.B., Tortelli F.P., Riet-Correa B., Ferreira J.L.M., Soares M.P., Farias N.A.R., Riet-Correa F., Schild A.L. 2006. Tick fever in Southern Brazil: a retrospective study of 1978-2005 (Tristeza parasitária bovina na região sul do Rio Grande do Sul: estudo retrospectivo de 19782005). Pesq. Vet. Bras. 26:237-242.

2. Bock R., Jackson L., De Vos A., Jorgensen W. 2014. Babesiosis of cattle. Parasitology 129, 247-269.

3. Costa S.C.L., Magalhães V.C.S., Oliveira U.V., Carvalho F.S., Almeida C.P., Machado R.Z., Munhoz A.D. 2016. Transplacental transmission of bovine tick-borne pathogens: Frequency, co-infections and fatal neonatal anaplasmosis in a region of enzootic stability in the northeast of Brazil. Ticks Tick Borne Dis. 7:270-275.

4. Henker L.C., Lorenzett M.P., Fagundes-Moreira R., Dalto A.G.C., Sonne L., Driemeier D., Soares J.F., Pavarini, S.P. 2020. Bovine abortion, stillbirths, and neonatal death associated with Babesia bovis and Anaplasma sp. infections in southern Brazil. Ticks and Tick-borne Diseases, 11 (4):101443. 
5. Mello L.S., Bianchi M.V., Bandinelli M.B., Sonne L.,

Braz J Vet Pathol, 2021, 14(1), 70 - 74

DOI: 10.24070/bjvp.1983-0246.v14i1p70-74

Driemeier D., Pavarini S.P. 2017. Causes of death in dairy cows in Rio Grande do Sul (Causas de morte em vacas leiteiras no Rio Grande do Sul). Pesq. Vet. Bras. 37:916-920.

6. Pupin R.C., Guizelini C.C., Lemos R.A.A., Martins T.B., Borges F.A., Borges D.G.L., Gomes D.C. 2019. Retrospective study of epidemiological, clinical and pathological findings of bovine babesiosis in Mato Grosso do Sul, Brazil (1995 -2017). Ticks Tick Borne Dis. 10:36-42.

7. Trueman K.F., Mclennan M.W. 1987. Bovine abortion due to prenatal Babesia bovis infection. Aust. Vet. J. 64:63.

8. Wright I.G., Goodger B.V., Buffington G.D., Clark I.A., Parrodi F., WaltisbuhL D.J. 1989. Immunopathophysiology of babesial infections. Trans. R. Soc. Trop. Med. Hyg. 83:11-13.

9. Valli V.E.O., Kiupel M., Bienzle D. 2016. Hematopoietic system: hemolytic anemia, p. 114-119. in: Maxie M.G. (Ed.). Jubb, Kennedy, and Palmer's Pathology of Domestic Animals, 6th ed., Vol. 3, Elsevier, Amsterdam. 